17,01

\title{
Углеродный композит на основе фуллеренов и терморасширенного графита
}

\author{
(C) В.И. Берёзкин ${ }^{1}$, В.В. Попов ${ }^{2}$, М.В. Томкович ${ }^{2}$ \\ ${ }^{1}$ Научно-исследовательский центр экологической безопасности РАН, \\ Санкт-Петербург, Россия \\ ${ }^{2}$ Физико-технический институт им. А.Ф. Иофффе РАН, \\ Санкт-Петербург, Россия \\ E-mail: v.berezkin@inbox.ru
}

(Поступила в Редакцию 27 июля 2016 г.)

Синтезирован и исследован углеродный композиционный материал на основе фуллеренов и терморасширенного графита при разных их соотношениях (от 16:1 до 1:16 по массе). Образцы получены путем внедрения $\mathrm{C}_{60}$ в проводящую матрицу в результате термообработки исходных дисперсных смесей в вакуумном диффузионно-адсорбционном процессе, их дальнейшего холодного прессования и отжига. Показано, что между фуллеренами и окружением образуются ковалентные связи. Электропроводность образцов довольно высокая и находится в пределах от единиц до сотен $(\Omega \cdot \mathrm{cm})^{-1}$. Концентрация носителей заряда (преимущественно дырок) составляет $\sim 10^{19}-10^{20} \mathrm{~cm}^{-3}$. Сделан вывод, что материал при использованных соотношениях компонентов можно отнести к металлическим системам со структурным беспорядком.

Работа выполнена при частичной поддержке РФФИ (грант № 14-03-00496) и программы Президиума РАН (П-20).

DOI: $10.21883 /$ FTT.2017.03.44177.311

\section{1. Введение}

Композиционные материалы, как известно [1], обычно состоят из вмещающей матрицы и наполнителя или чередующихся слоев различных компонентов или фаз. Составляющие части могут находиться в механическом контакте или связываться химически. Композиты обладают рядом уникальных свойств, поэтому они давно и успешно применяются в самых разных областях.

Углеродные композиты приобрели сегодня особую значимость в связи с возможностью создания на их основе разнообразных электронных устройств. Так, чередуя $s p^{2}$ - и $s p^{3}$-области микро- и нанометровых размеров, можно создавать слоистые композиции типа металл-диэлектрик-металл, металл-диэлектрикполупроводник [2,3]. Подобные структуры считаются перспективными для применения, например, в фотоприемниках, светоизлучающих устройствах, для использования в качестве холодных катодов, для создания сверхпроводников.

Сверхпроводимость обнаружена в целом ряде углеродных материалов [1]. В частности, она наблюдается при введении в молекулярные фуллереновые структуры (пленки, кристаллы, поликристаллические порошки) атомов ряда металлов (щелочных, щелочно-земельных, редкоземельных) [4]. Однако интеркалированные металлами фуллереновые сверхпроводники крайне нестабильны. В воздушной среде они быстро (за доли секунды [5]) теряют сверхпроводимость вследствие окисления металлических примесей.

Одним из способов стабилизации сверхпроводящего состояния может быть создание таких композиционных материалов, в которых легированные фуллерены размещаются в проводящей матрице, причем химически связываются с ней. Естественной матрицей (связующим веществом) для такого композита представляется другая углеродная структура. Поскольку твердый углерод существует в самых разнообразных модификациях, вполне возможно подобрать такую, которая обеспечит создание композитов с химическими связями между компонентами. При достаточном содержании в материале сверхпроводящей фазы именно она и будет главным образом определять характер его электропроводности.

Принципиальная возможность реализации данной идеи была впервые продемонстрирована в работе [6]. В [7] было показано, что в таком материале наблюдаются эффекты, характерные для сверхпроводящего состояния. В целом в работах [6,7] был представлен новый класс углеродных композитов, в котором фуллерены и легирующие примеси (донорные и акцепторные) помещены в углеродную матрицу. При легировании натрием было получено стабильное на воздухе состояние, трактуемое как сверхпроводящее при температуpax $T \leq 15 \mathrm{~K}$. Указанные композиты синтезированы с помощью ,алмазной“ технологии, т. е. путем воздействия высоких давлений и температур на исходные механические смеси. Последние содержали фуллерены, углеводородные связующие вещества (нафталин $\mathrm{C}_{10} \mathrm{H}_{8}$ и др.), а также соединения с легирующими элементами. Для алмазной технологии, как хорошо известно, характерны существенные неоднородности целого ряда параметров в зоне синтеза (в том числе давления, температуры, распределения вещества), что приводит к слабой воспроизводимости результатов. 
В настоящей работе представлены нелегированные материалы, аналогичные синтезированным в [6,7], но полученные в условиях, обеспечивающих более высокую однородность параметров в рабочей зоне, исследованы некоторые их оптические и электрические свойства.

\section{2. Экспериментальные образцы и измерения}

В качестве связующего вещества использован терморасширенный графит (ТРГ). Его получают путем быстрого нагрева интеркалированного минеральными кислотами (серной или азотной) тонко смолотого графита, как правило природного (его обычная плотность равна $\left.2.08-2.23 \mathrm{~g} / \mathrm{cm}^{3}[1]\right)$. Частицы графита вспучиваются, расстояния между атомными слоями увеличиваются в сотни раз. В результате образуется дисперсная субстанция с очень низкой насыпной плотностью $\left(1.5-5.0 \mathrm{~kg} / \mathrm{m}^{3}[8]\right)$, сравнимой с плотностью сухого

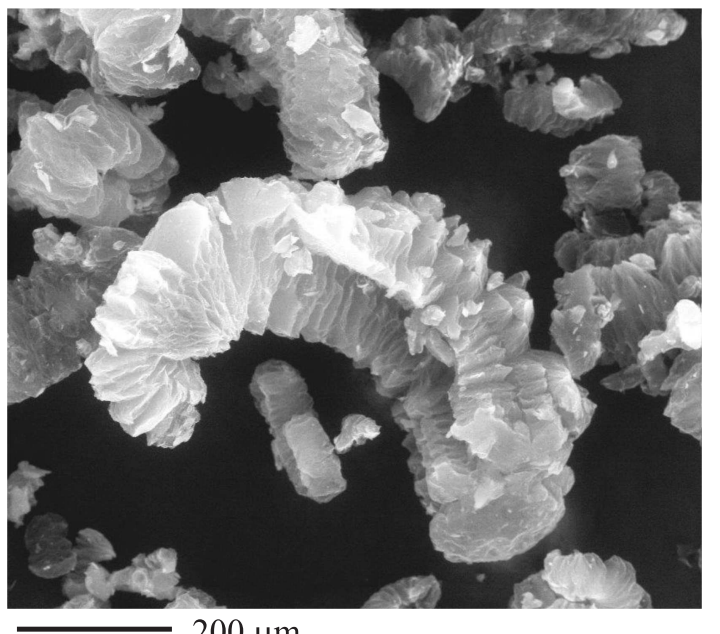

$a$

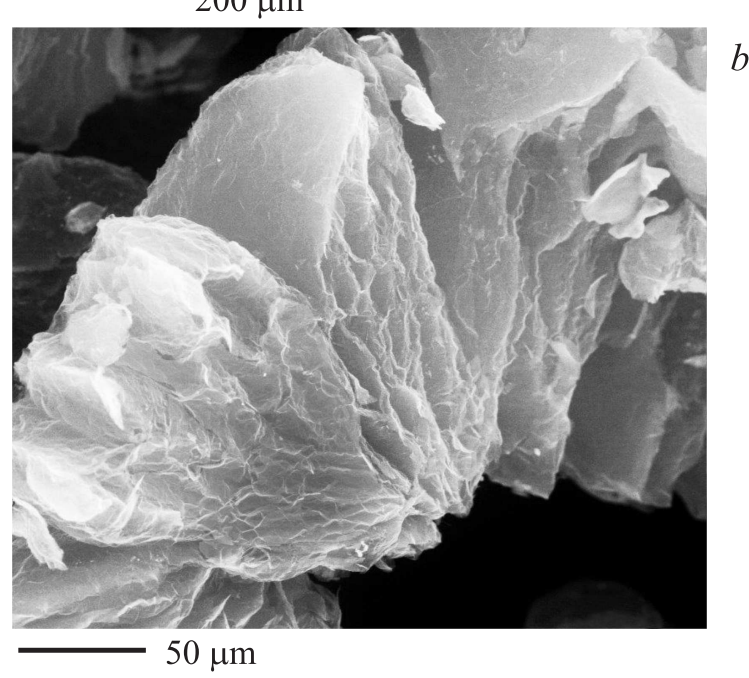

Рис. 1. Изображение ТРГ, полученное в растровом электронном микроскопе. $a-$ общий план, в центре видна типичная для ТРГ червеобразная частица, $b-$ ее увеличенный фрагмент.
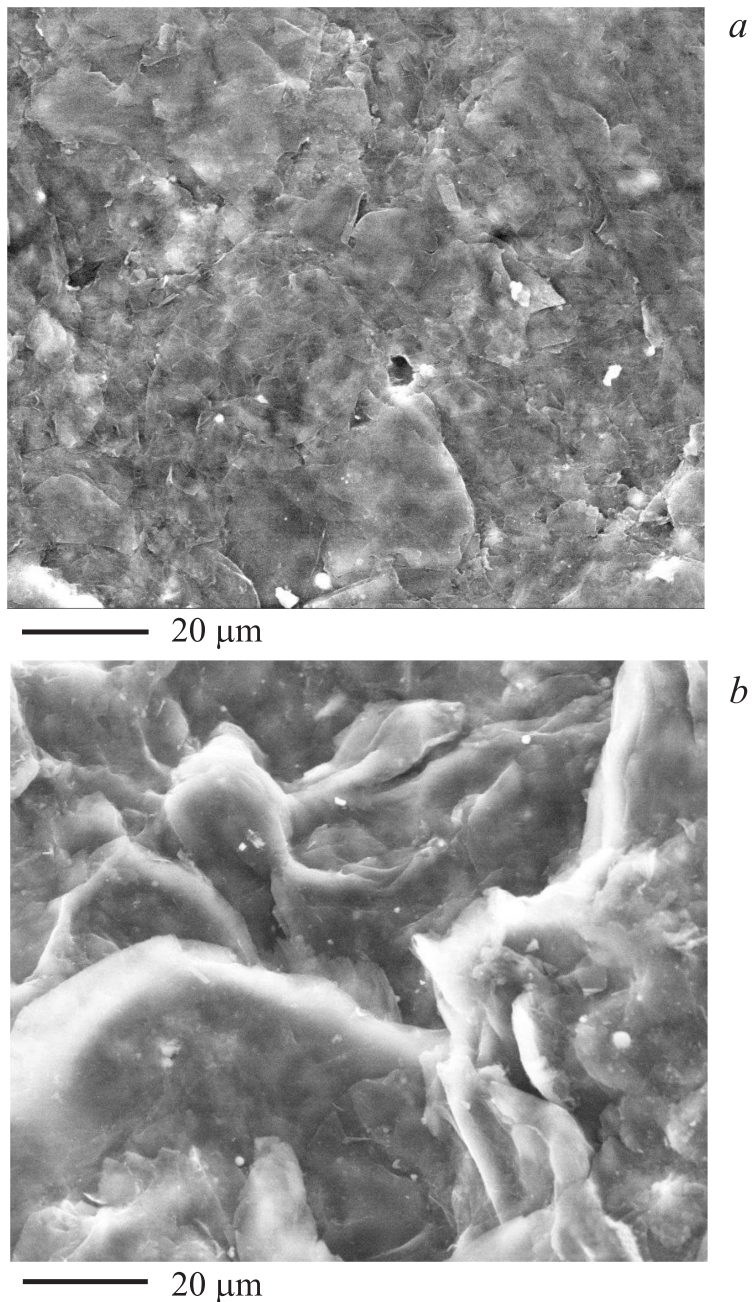

Рис. 2. Изображения образца ТРГ, спрессованного при давлении $0.7 \mathrm{GPa} . a-$ поверхность, $b-$ скол.

воздуха $\left(1.29 \mathrm{~kg} / \mathrm{m}^{3}\right.$ при $0^{\circ} \mathrm{C}$ и 760 Torr [9]). На рис. 1 показано изображение ТРГ, использованного в настоящей работе. Видно, что он состоит из отдельных частиц с ярко выраженной слоистой структурой.

ТРГ пригоден для холодной формовки (прокатки, прессования) без связующих веществ. В результате получают гибкие листовые материалы, в том числе углеродные фольги и другие изделия. Они имеют темносерый с матовым блеском цвет. Их плотность лежит в пределах $0.5-1.6 \mathrm{~g} / \mathrm{cm}^{3}$ при наиболее характерной величине $\sim 1.0 \mathrm{~g} / \mathrm{cm}^{3}$. В самых плотных образцах она может достигать $2.16 \mathrm{~g} / \mathrm{cm}^{3}$. Так что наиболее плотные прессованные из ТРГ образцы по цвету и плотности соответствуют природному кристаллическому графиту высокого качества. Иными словами, в твердой фазе при комнатной температуре $\left(T=T_{\text {room }}\right)$ эффективно осуществляется химическая реакция непосредственного объединения („полимеризации“) частиц ТРГ в плотный низкопористый углеродный монолит. Можно отметить, что в отличие от ТРГ такие материалы, как, например, 

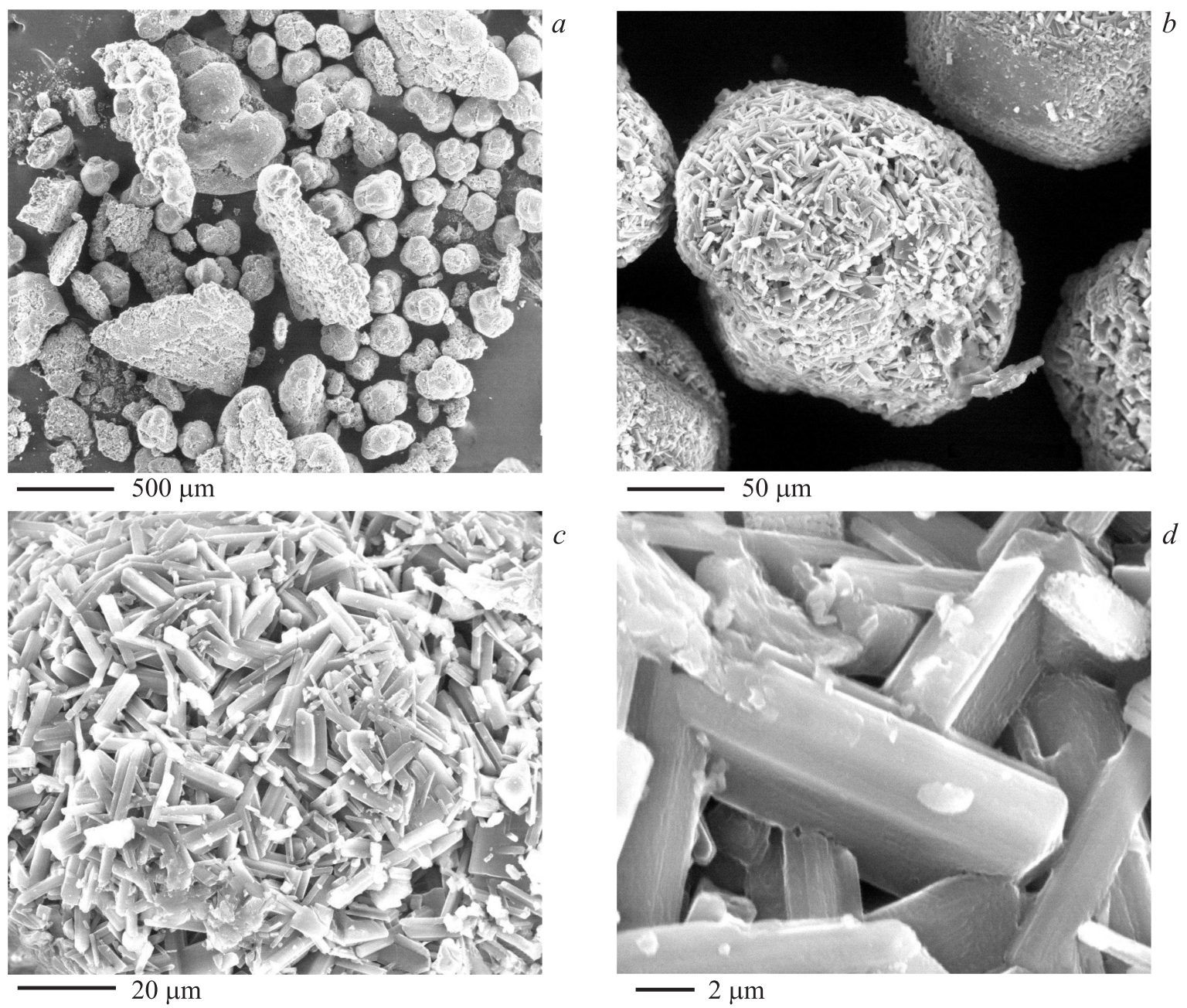

Рис. 3. Изображения поликристаллического порошка фуллерена $\mathrm{C}_{60}(a)$ и отдельной его частицы из верхней части фотографии при различных увеличениях $(b-d)$.

углеродные сажи или активные угли, без связующих веществ не прессуются. На рис. 2 показан результат прессования ТРГ при давлении $0.7 \mathrm{GPa}$. Видно, что образуется сплошная структура. На рис. 2, а хорошо заметны крупные поверхностные поры (в центре и слева).

Наши исследования показали, что ТРГ является высокоэффективным углеродным адсорбентом, который по параметрам не уступает активным углям. Он вполне может вмещать в себя фуллерены и другие вещества, исполняя при определенных условиях роль хорошо проводящей среды-матрицы и обеспечивая эффективные электрические взаимодействия всех компонентов.

По поводу фуллеренов хорошо известно, что их поликристаллические порошки уже под воздействием относительно невысоких внешних приложенных давлений (до $2 \mathrm{GPa}$ ) и также при $T=T_{\text {room }}$ легко полимеризуются в довольно прочные монолитные образцы. Например, полимерная фаза образуется даже при давлении величиной $0.3 \mathrm{GPa}[10]$. Для иллюстрации на рис. 3 показан исходный поликристаллический порошок фуллерена $\mathrm{C}_{60}$. Хорошо видно, что его частицы состоят из отдель- ных микрокристаллов. После воздействия внешнего давления величиной $0.7 \mathrm{GPa}$ такая микрокристаллическая структура уже не наблюдается, рис. 4.

При повышенных температурах (примерно от $400^{\circ} \mathrm{C}$ и выше) исходные фуллерены сублимируются, а при 700-900 ${ }^{\circ} \mathrm{C}$ (по данным разных авторов [10]) их молекулы начинают разрушаться вне зависимости от величины внешнего давления.

Учитывая все отмеченное выше, для синтеза была выбрана следующая процедура. Механические смеси ТРГ и поликристаллических порошков $\mathrm{C}_{60}$ при различных их соотношениях помещались в стеклянные ампулы, которые откачивались форвакуумным насосом и отпаивались. Далее следовали нагрев до $550-650^{\circ} \mathrm{C}$ в течение $0.5-1 \mathrm{~h}$ и выдержка в течение $5 \mathrm{~h}$, так что $\mathrm{C}_{60}$ испарялся и компоненты перемешивались в довольно длительном диффузионно-адсорбционном процессе. После этого печь выключалась, полученные дисперсные продукты остывали вместе с ней. Затем они извлекались на воздух и при давлении $0.7 \mathrm{GPa}$ и $T=T_{\text {room }}$ прессовались в пластины диаметром $13 \mathrm{~mm}$ и толщиной око- 
ло $1 \mathrm{~mm}$. Отжиг пластин $\left(550-650^{\circ} \mathrm{C}, 5 \mathrm{~h}\right)$ проводился в вакууме. Из них вырезались образцы нужной формы.

В итоге получены отожженные и неотожженные образцы при девяти разных исходных соотношениях $\mathrm{C}_{60}$ :ТРГ, а именно $1: 16,1: 8,1: 4, \ldots, 16: 1$ (по массе). Типичное изображение материала на примере одного из синтезированных образцов показано на рис. 5. Видно, что он довольно плотный и однородный.

Все образцы имели темно-серый с матовым блеском цвет. В них исследован ряд электрических, гальваномагнитных, оптических и других свойств. Получены зависимости удельного электросопротивления $\rho(T)$ в диапазоне от $T=4.2 \mathrm{~K}$ до $T=T_{\text {room, постоянной }}$ Холла $R_{H}(H)$ при напряженностях магнитного поля $H=0-25 \mathrm{kOe}$ и при $T=77 \mathrm{~K}$. Для этого использованы стандартные четырехзондовые методики. Измерены спектры оптического пропускания при $T=T_{\text {room в обла- }}$ сти частот колебательных мод молекулы $\mathrm{C}_{60}$, а именно в инфракрасном (ИК) диапазоне $400-1500 \mathrm{~cm}^{-1}$. Ис-
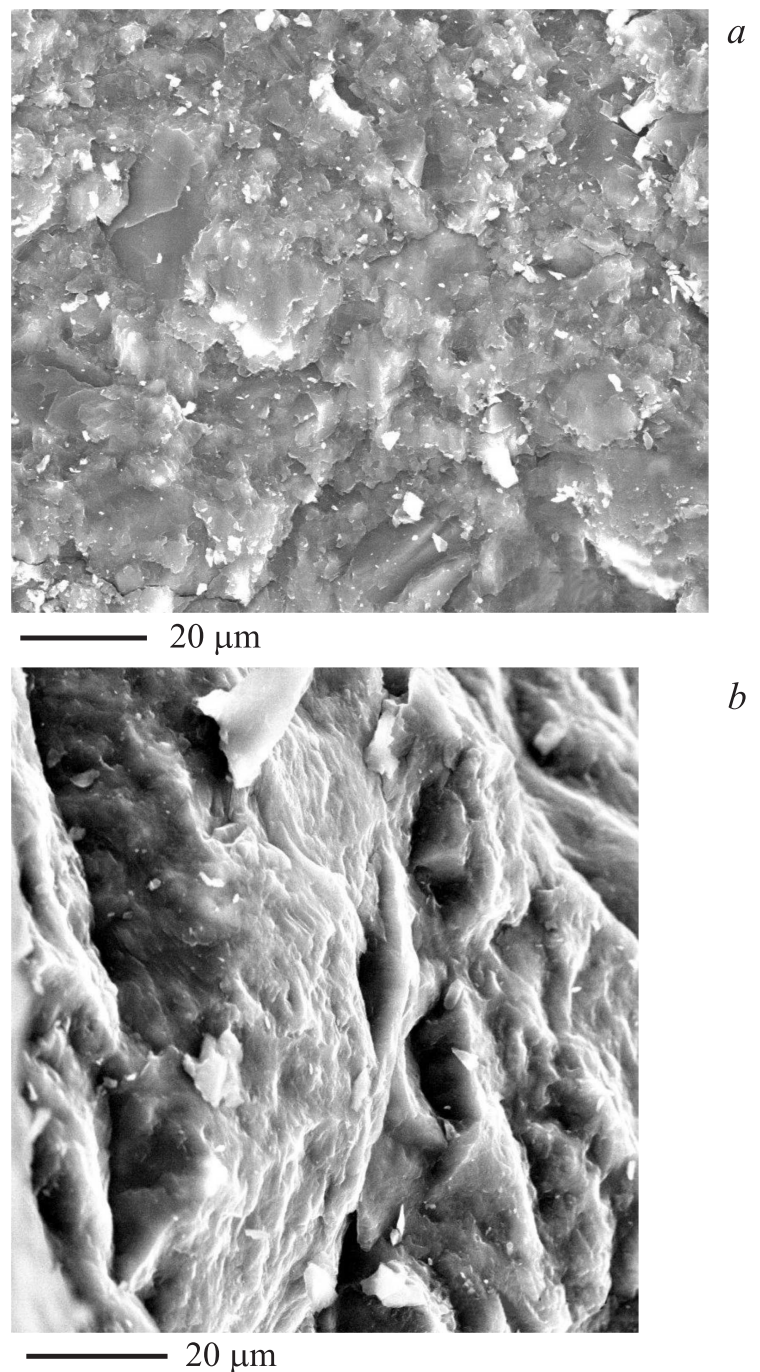

$b$

Рис. 4. Образец порошка поликристаллического фуллерена $\mathrm{C}_{60}$ после воздействия на него внешнего давления величиной $0.7 \mathrm{GPa} . a-$ поверхность, $b-$ скол.

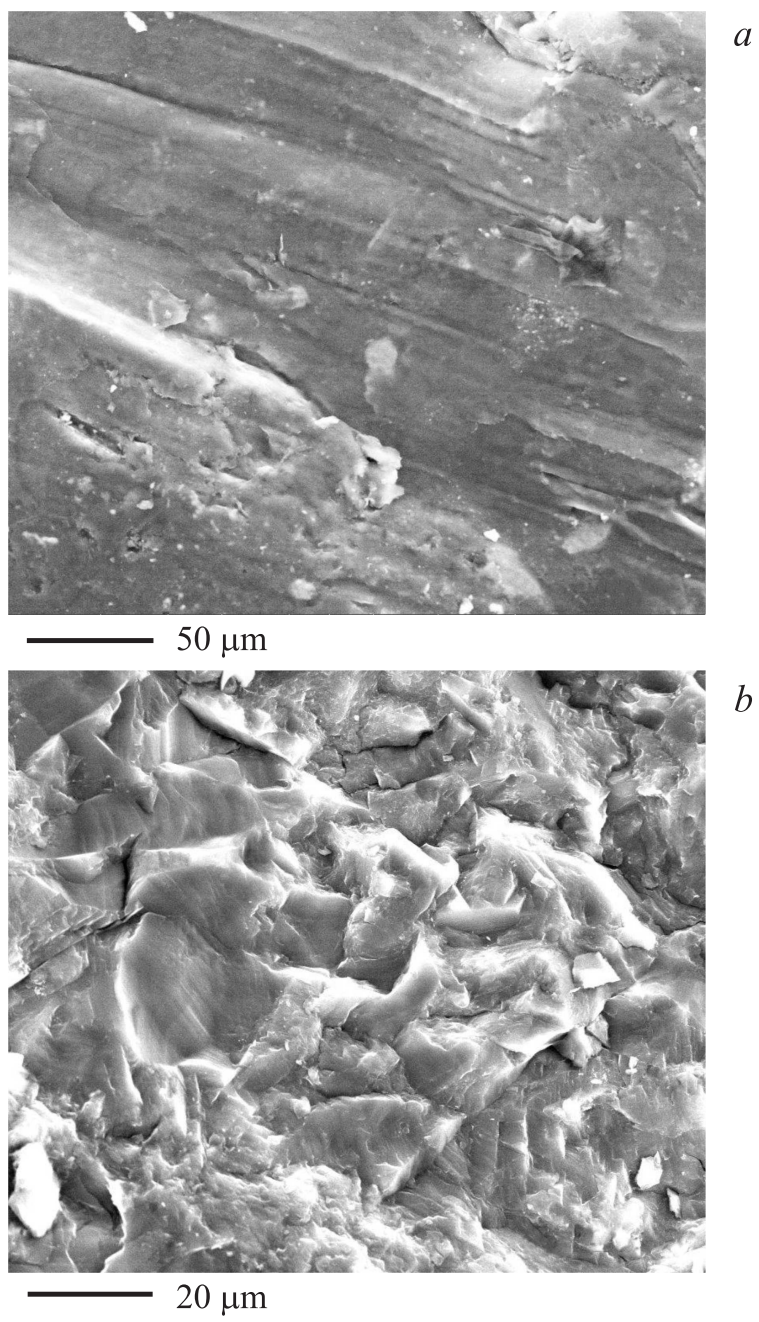

Рис. 5. Изображения синтезированного композиционного материала $\mathrm{C}_{60}+$ ТРГ на примере образца с исходным массовым соотношением компонентов $1: 1 . a-$ поверхность, $b-$ скол.

пользована стандартная для таких измерений процедура: образцы размалывались и прессовались в таблетки KBr.

Для сравнения измерены некоторые параметры образцов, полученных из чистых ТРГ и $\mathrm{C}_{60}$ (образцы из $\mathrm{C}_{60}$ не отжигались во избежание деполимеризации).

\section{3. Результаты и обсуждение}

3.1. ИК-спектры пропускания. Прежде всего необходимо выяснить, являются полученные материалы простыми механическими смесями $\mathrm{C}_{60}+$ ТРГ или между матрицей и наполнителем (т.е. между частицами графита и молекулами $\mathrm{C}_{60}$ ) образуется ковалентная связь, пусть даже частично. Прямыми доказательствами как того, так и другого могли бы послужить данные о колебательных состояниях молекул $\mathrm{C}_{60}$ в объеме образцов. Такие данные обычно получают методами комбинационного рассеяния света (КРС), ИК-спектроскопии, а также неупругого рассеяния нейтронов. Дело в том, что 
при вступлении фуллеренов в ковалентную связь при полимеризации или образовании соединений с другими веществами симметрия молекул $\mathrm{C}_{60}$ (икосаэдрическая группа $I_{h}$ ) резко изменяется (понижается), так что существенные изменения в спектрах наблюдаются уже при комнатной температуре. Напротив, в молекулярных фуллереновых конденсатах молекулы при $T=T_{\text {room }}$ вращаются почти свободно, поэтому спектры практически не отличаются от соответствующих спектров отдельной молекулы.

Колебательные моды $\mathrm{C}_{60}$ теоретически и экспериментально исследованы еще на начальных стадиях изучения фуллеренов [11-15]. Подробно характеризовать их не будем, а напомним лишь те основные моменты, которые важны для нас. В симметрии $I_{h}$ разрешено вырождение $1,3,3,4$, 5. В спектрах эти моды обозначаются как $A, T_{1}, T_{2}, H, G$ соответственно. Индексами $g$ и $u$ обозначают переходы между уровнями с сохранением и изменением четности волновой функции. $\mathrm{B}$ свободной молекуле $\mathrm{C}_{60}$ число внутренних степеней свободы равно 174. Однако ввиду высокой точечной симметрии молекулы фундаментальными в соответствии с неприводимыми представлениями являются только 46 колебательных мод, а именно

$$
\begin{aligned}
\Gamma_{\mathrm{mol}}=2 A_{g}(\mathrm{R}) & +3 T_{1 g}+4 T_{2 g}+6 G_{g}+8 H_{g}(\mathrm{R})+A_{u} \\
& +4 T_{1 u}(\mathrm{IR})+5 T_{2 u}+6 G_{u}+7 H_{u}
\end{aligned}
$$

Из них активными являются только десять мод $\left(2 A_{g}+8 H_{g}\right)$ в спектрах КРС (R) и только четыре $T_{1 u}$-моды в ИК (IR)-спектрах поглощения/пропускания. B спектрах все они хорошо заметны и легко регистрируются. В частности, оптически активные моды $T_{1 u}(1)$, $T_{1 u}(2), T_{1 u}(3)$ и $T_{1 u}(4)$ характеризуются в ИК-спектрах частотами 526, 576, 1183 и $1429 \mathrm{~cm}^{-1}$ соответственно. Остальные 32 моды являются немыми, поскольку запрещены правилами отбора. Они и в тех, и в других спектрах не проявляются или проявляются слабо.

При изучении производных фуллеренов методами колебательной спектроскопии зачастую предпочитают данные по ИК-спектрам в силу ряда причин. Например, это связано с наличием обширных справочных данных по ИК-спектрам, что удобно для анализа структуры присоединенных к $\mathrm{C}_{60}$ гетеромолекул, особенно органических. С помощью ИК-спектров возможна также качественная идентификация фуллеренов, при этом наиболее подходящей для обнаружения $\mathrm{C}_{60}$ является длинноволновая полоса поглощения при $526 \mathrm{~cm}^{-1}$, поскольку обычно она самая интенсивная.

Хорошо известно, что в результате воздействия на фуллерены и их соединения повышенных давлений (в том числе в сочетании с повышенными температурами) интенсивность данной полосы по отношению к более коротковолновым полосам, соответствующим другим активным модам, может изменяться, причем в зависимости от условий в обе стороны, т. е. как в сторону уменьшения [16], так и в сторону увеличения [17].
Немые моды могут становиться активными, может наблюдаться расщепление ИК-линий вследствие снятия вырождения, возможно появление новых полос, в том числе типа обертонов и сложных колебаний (двойных комбинаций фундаментальных мод). При этом немые моды могут наблюдаться одновременно в ИК- и КРСспектрах (что невозможно для активных мод), а также в нейтронных спектрах. По данным [14] при приложении к $\mathrm{C}_{60}$ даже небольших давлений, до $8 \mathrm{kbar}(0.8 \mathrm{GPa})$, может происходить сдвиг по частоте как активных, так и немых мод, который может достигать $20 \mathrm{~cm}^{-1}$. В наших образцах практически все перечисленные эффекты имеют место.

На рис. 6 представлены типичные ИК-спектры пропускания, измеренные при $T=T_{\text {room. }}$. На всех зависимостях хорошо видны особенности, соответствующие ИК-активным колебательным модам. В исходном (свободном) $\mathrm{C}_{60}$ (кривая 1) интенсивности полос при 526, 576, 1183 и $1429 \mathrm{~cm}^{-1}$ соотносятся как $1: 0.60: 0.27: 0.24$. После воздействия на него давления величиной $0.7 \mathrm{GPa}$ (кривая 2) получается соотношение $1: 0.57: 0.43: 0.31$. Для образца, приготовленного из смеси $\mathrm{C}_{60}:$ ТРГ $=16: 1$, имеем $1: 0.37: 0.24: 0.26$ (кривая 3), для состава $\mathrm{C}_{60}:$ ТРГ $=1: 4$ (кривая 4)$1: 0.28: 0.22: 0.22$. Иными словами, относительные изменения интенсивностей разрешенных полос поглощения $\mathrm{C}_{60}$ хорошо заметны. Отметим, что отжиги образцов также приводят к вполне заметным аналогичным изменениям (до $15 \%$ в ту или иную сторону).

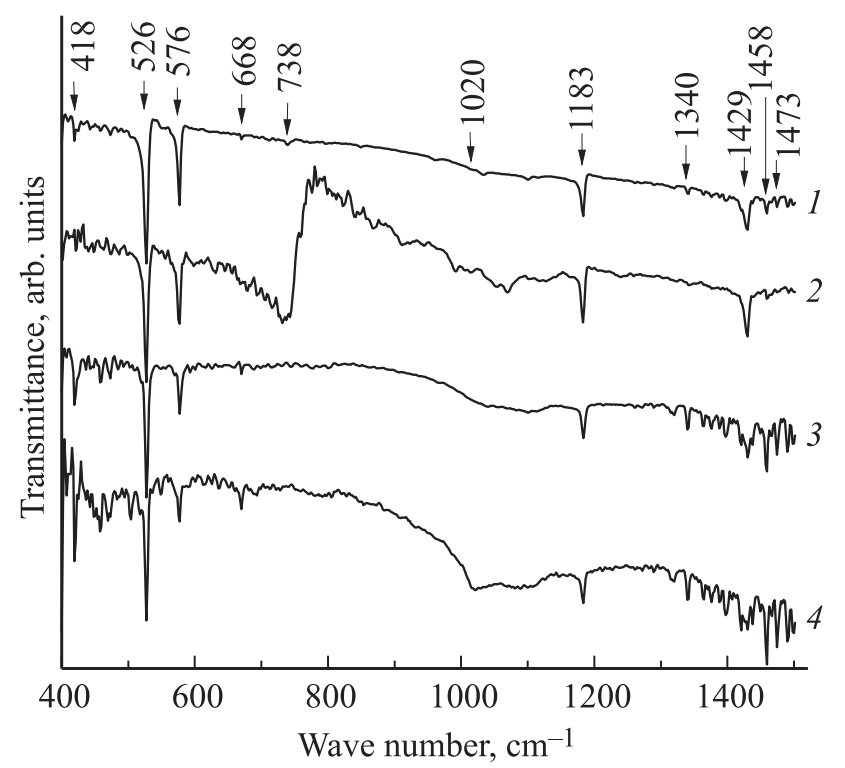

Рис. 6. Типичные ИК-спектры пропускания (в произвольных единицах) образцов при $T=T_{\text {room в области частот колебатель- }}$ ных мод молекулы $\mathrm{C}_{60}$. Стрелками обозначены частоты, при которых располагаются особенности, упоминаемые в тексте, 1 - исходный (свободный) $\mathrm{C}_{60} ; 2-$ он же после воздействия внешнего давления величиной $0.7 \mathrm{GPa} ; 3$ - образец, полученный из исходного состава $\mathrm{C}_{60}:$ ТРГ $=16: 1 ; 4$ - образец, полученный из состава $\mathrm{C}_{60}:$ ТРГ $=1: 4$. 
Что касается слабых особенностей, то, например, полоса при $418 \mathrm{~cm}^{-1}$ на кривой 1 становится весьма развитой в спектрах 3 и 4. Ей можно сопоставить моду $H_{g}(2)$, проявляющуюся в ромбоэдрической полимерной фазе $\mathrm{C}_{60}$ при $415 \mathrm{~cm}^{-1}$ [17]. Вероятно, немая в свободном $\mathrm{C}_{60}$ мода $H_{g}(2)$ в наших образцах типа $\mathrm{C}_{60}+\mathrm{TP \Gamma}$ становится активной.

Слабая особенность на кривых $1-3$ при $668 \mathrm{~cm}^{-1}$, соответствующая моде $H_{u}(3)$, хорошо видна на кривой 4 . Здесь же справа от нее $\left(692 \mathrm{~cm}^{-1}\right.$, кривая 4$)$ становится заметной особенность, которой можно сопоставить комбинацию двух мод $H_{u}(1)+T_{2 u}(1)$ с частотами 342 и $353 \mathrm{~cm}^{-1}$ соответственно. Отметим, что в [14] мода при $668 \mathrm{~cm}^{-1}$ в исходном кристалле $\mathrm{C}_{60}$ при $T=300 \mathrm{~K}$ также была очень слабой. В том же образце при $T=77 \mathrm{~K}$ (вращение молекул заморожено) она гораздо более заметна. После обработки кристалла высоким давлением величиной $25 \mathrm{kbar}(2.5 \mathrm{GPa})$ она становилась хорошо заметной и при $T=300 \mathrm{~K}$. Иными словами, как охлаждение $\mathrm{C}_{60}$ в [14] до температур ниже температуры стекольного фазового перехода $(T \approx 90 \mathrm{~K})$, при которой происходит ротационное замораживание молекул, так и приложение внешнего давления в [14] и настоящей работе действуют на эту моду одинаково: оба фактора понижают симметрию молекулы. В первом случае это может происходить за счет роста влияния кристаллического поля, дефектов и примесей, поверхностных и изотопических эффектов и т.д. Во втором - это возможно, если после снятия давления между молекулами $\mathrm{C}_{60}$ в кристалле (по крайней мере, между некоторой их частью) сохраняются ковалентные связи.

Едва заметная особенность при $738 \mathrm{~cm}^{-1}$ на кривой 1 (рис. 6), соответствующая моде $G_{u}(2)$, трансформируется на кривой 2 в мощную широкую полосу поглощения с центральной частью, расщепленной на четыре полосы при 724, 730, 736 и $742 \mathrm{~cm}^{-1}$. На кривой 2 появляется также масса мелких, но хорошо различимых полос, которым можно сопоставить целый ряд немых мод, в том числе комбинированных. Например, особенности при $1020 \mathrm{~cm}^{-1}$ отвечает комбинация мод $H_{g}(1)+G_{u}(3)$ с частотами 267 и $753 \mathrm{~cm}^{-1}$. На кривых 1 и 2 она едва заметна, на кривой 3 ее нет, на кривой 4 на этой частоте располагается хорошо заметная широкая бесструктурная полоса.

Слабая на кривых 1 и 2 полоса при $1340 \mathrm{~cm}^{-1}$ очень хорошо видна на кривых 3 и 4. Она соответствует комбинации $T_{2 g}(2)+H_{u}(2)$ с частотами 764 и $579 \mathrm{~cm}^{-1}$.

Разрешенная в ИК-спектрах полоса $T_{1 u}(4)$ при $1429 \mathrm{~cm}^{-1}$ на кривых 3 и 4 отчетливо расщеплена на три полосы (при этом боковые частоты равны 1419 и $\left.1436 \mathrm{~cm}^{-1}\right)$.

Небольшие особенности на кривых 1 и 2 при 1458 и $1473 \mathrm{~cm}^{-1}$ хорошо развиты на кривых 3 и 4 . Обе эти полосы можно связать с чувствительной к полимеризации модой $A_{g}(2)$, которая, как видно из выражения (1), в свободном $\mathrm{C}_{60}$ является раман-активной, а в ИК-спектрах — немой. В свободном $\mathrm{C}_{60}$ данная мода проявляется при частотах, близких к $1470 \mathrm{~cm}^{-1}$, в различных полимерных фазах она характеризуется разными частотами. Например, в орторомбической фазе ее частота по данным [17] равна $1457 \mathrm{~cm}^{-1}$.

Таким образом, фононные спектры $\mathrm{C}_{60}$ в образцах существенно изменяются, что, на наш взгляд, вполне можно считать прямым доказательством наличия в представленном материале ковалентных связей фуллеренов с окружением.

3.2. Пористость образцов. Плотность полученных образцов $\mathrm{C}_{60}+$ ТРГ лежит в пределах от $1.27 \mathrm{~g} / \mathrm{cm}^{3}$ (состав $\mathrm{C}_{60}:$ ТРГ $\left.=16: 1\right)$ до $1.74 \mathrm{~g} / \mathrm{cm}^{3}\left(\mathrm{C}_{60}:\right.$ ТРГ $\left.=1: 16\right)$. Плотность образцов из чистого $\mathrm{C}_{60}$ равна $1.50 \mathrm{~g} / \mathrm{cm}^{3}$, из чистого ТРГ $-1.80 \mathrm{~g} / \mathrm{cm}^{3}$. Поскольку плотность кристалла $\mathrm{C}_{60}$ равна $1.69 \mathrm{~g} / \mathrm{cm}^{3}$ [18], а теоретическая плотность графита $-2.265 \mathrm{~g} / \mathrm{cm}^{3}$ [19], можно сделать вывод, что все наши образцы являются довольно пористыми, как впрочем и любые другие прессованные материалы в отличие, например, от плавленых. Поэтому важно знать, насколько они пористые и как это может повлиять на электронные и другие свойства.

Относительную пористость материала $P$ можно оценить следующим образом. Ее величина равна

$$
P=\frac{V_{P}}{V}=1-\frac{V_{0}}{V},
$$

где $V_{P}$ - объем пор, $V_{0}$ - объем материала, $V=V_{P}+V_{0}$ - общий объем пористого тела. В многокомпонентных твердых телах объем $V_{0}$ есть сумма объемов исходных компонентов. При наличии двух компонентов с плотностями $r_{01}$ и $r_{02}$ и массовым содержанием $m_{1}$ и $m_{2}$ (в нашем случае это плотности монокристаллов $\mathrm{C}_{60}$ и графита) из формулы (2) получаем

$$
P=1-\frac{r}{r_{0} r_{02}}\left(r_{01} \frac{m_{2}}{M}+r_{02} \frac{m_{1}}{M}\right),
$$

где $M=m_{1}+m_{2}$ - общая масса образца, $r=M / V-$ его измеренная плотность. Аналогичные формулы нетрудно получить для большего числа компонентов. Если имеется один компонент, из формулы (3) следует

$$
P=1-\frac{r}{r_{0}}
$$

Оценки по формулам (3) и (4) показывают, что в наших образцах из чистого $\mathrm{C}_{60} P=11 \%$; в образцах, где присутствует ТРГ, $P=14-29 \%$ (в среднем $P=22-23 \%)$; в чистом ТРГ $P=20 \%$. Для пористых материалов это не так уж много. Напротив, для таких высокопористых твердых тел, как, например, активные угли, имеет место обратная ситуация: пористость равна $70-80 \%$ (иначе говоря, материал занимает только $20-30 \%$ от общего объема образца).

Измерения показали, что удельное сопротивление исследуемых образцов (кроме чистого $\mathrm{C}_{60}$ ) невысокое и находится в пределах от единиц $\mathrm{m} \Omega \cdot \mathrm{cm}$ до десятых долей $\Omega \cdot \mathrm{cm}$. Это на порядки ниже, чем в образцах, 
описанных в наших предыдущих работах [6,7]. Там при примерно такой же плотности $\left(r \sim 1.5 \mathrm{~g} / \mathrm{cm}^{3}\right)$ величины $\rho$ имели значения от десятых долей $\Omega \cdot \mathrm{cm}$ до сотен $\Omega \cdot \mathrm{cm}$.

Иными словами, есть основания полагать, что в полученном материале электрические контакты между зернами достаточно надежны, а пористость на механизмы переноса заряда в первом приближении влияет не слишком сильно.

Отметим также, что еще в ранних работах по $s p^{2}$ структурам углерода отмечалось [20], что, например, в пироуглеродах с плотностями от $r=1.20 \mathrm{~g} / \mathrm{cm}^{3}$ до $r=2.26 \mathrm{~g} / \mathrm{cm}^{3}$, т. е. от весьма пористых сильно разупорядоченных (практически аморфных) структур до плотных высокоориентированных пирографитов, температурные зависимости удельного электросопротивления обычно нечувствительны к таким макроскопическим факторам, как пористость или преимущественная ориентация микрокристаллитов, а определяются уровнем кристаллического совершенства материала (размерами микрокристаллитов и степенью их упорядоченности).

Ввиду отмеченных выше обстоятельств для учета пористости было использовано простое умножение удельного электросопротивления, полученного в эксперименте для реального пористого образца $\rho_{\text {exp }}$, на соответствующий числовой коэффициент:

$$
\rho_{0}=\rho_{\exp }(1-P)
$$

где $\rho_{0}$ - удельное электросопротивление непористого образца из того же материала.

3.3. Удельное электросопротивление. На рис. 7 с учетом пористости, рассчитанной по формуле (5), представлены температурные зависимости $\rho(T)$ образцов с разным содержанием $\mathrm{C}_{60}$. Видно, что с ростом доли фуллеренов величина $\rho$ увеличивается. На рис. 8 зависимость показана в линейном масштабе, на вставке она для наглядности представлена также в полулогарифмическом масштабе. Штриховые линии на рис. 8 и вставке к нему проведены для ориентировки. Рис. 7 и 8 отражают данные по всем полученным образцам, за исключением чистого $\mathrm{C}_{60}$, что связано с его высокоомностью, обусловленной следующими обстоятельствами.

Молекулярные кристаллы $\mathrm{C}_{60}$, которые характеризуются шириной запрещенной зоны $E_{g}=1.5-2.3 \mathrm{eV}$ (по данным разных авторов [21]), считаются, как известно, полупроводниками $n$-типа, однако практически это диэлектрики, у которых $\rho \sim 10^{6}-10^{7} \Omega \cdot \mathrm{cm}$. С ростом степени беспорядка $\rho$ возрастает. Во всех случаях в воздушной среде (т.е. при контакте с кислородом) $\rho$ увеличивается на три-шесть порядков и более, достигая значений $\sim 10^{14} \Omega \cdot \mathrm{cm}$. В полимерах, получаемых сжатием порошков $\mathrm{C}_{60}$, величина $\rho$ уменьшается. Например, в [22] после такой процедуры она снижалась на четыре порядка при достижении давления $20 \mathrm{GPa}$, причем до давления $8 \mathrm{GPa}$ она практически не изменялась. Поэтому температурный ход $\rho$ в различных объемных образцах

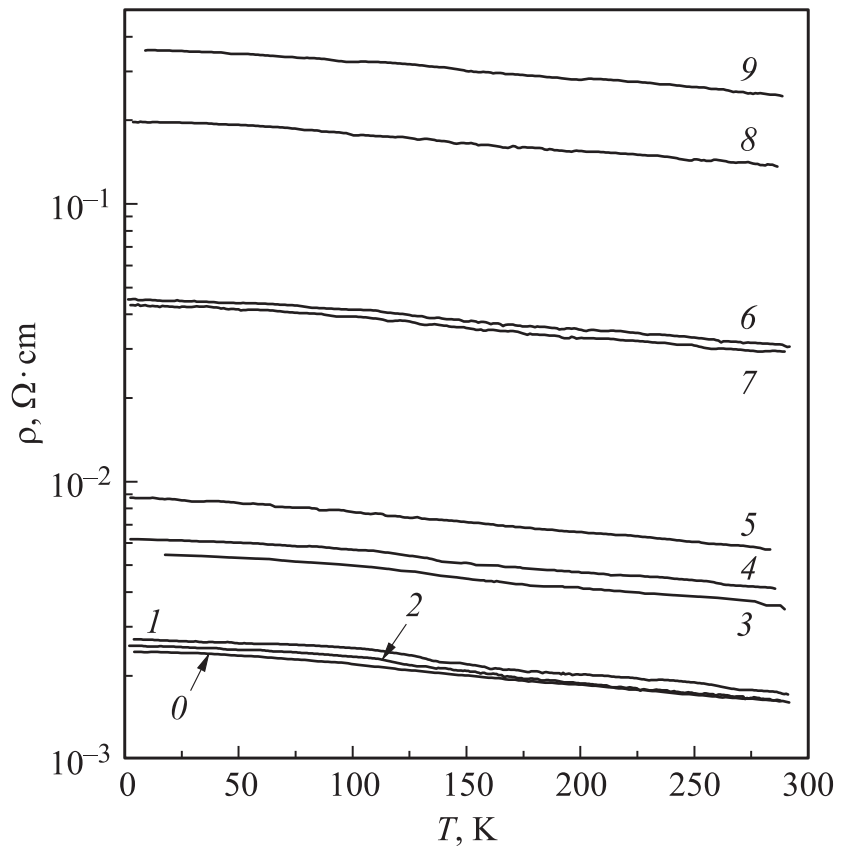

Рис. 7. Удельное сопротивление в зависимости от температуры отожженных образцов с разными соотношениями компонентов. 0 - образец без $\mathrm{C}_{60}$, т.е. чистый прессованный ТРГ; 1-9 - образцы с различными исходными соотношениями $\mathrm{C}_{60}:$ ТРГ по массе: $1-1: 16,2-1: 8,3-1: 4,4-1: 2$, $5-1: 1,6-2: 1,7-4: 1,8-8: 1,9-16: 1$.

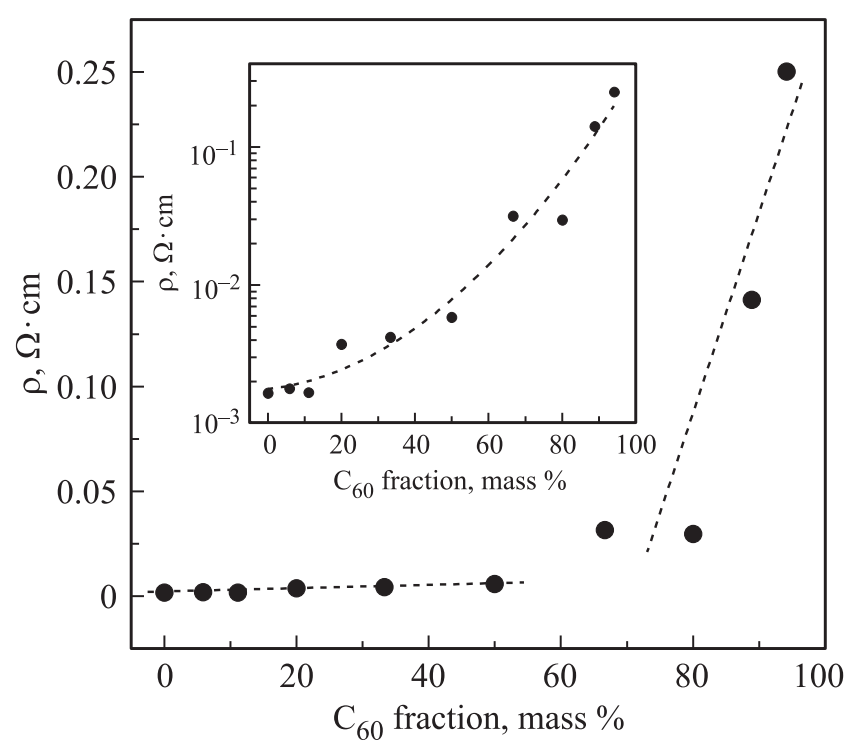

Рис. 8. Удельное сопротивление образцов при $T=273 \mathrm{~K}$ в зависимости от относительной доли $\mathrm{C}_{60}$. На вставке зависимость показана в полулогарифмическом масштабе. Штриховые линии проведены для ориентировки.

$\mathrm{C}_{60}$ чаще всего измеряют при $T>T_{\text {room. }}$ Для более низких температур обычно используют пленки.

Для наших прессованных образцов $\mathrm{C}_{60}$ экспериментальные оценки дают величины $\rho>10^{12} \Omega \cdot \mathrm{cm}$. Достаточно высокоомными являются также материалы типа 
$\mathrm{C}_{60}+$ ТРГ с более высоким содержанием $\mathrm{C}_{60}$, чем в представленных образцах.

В целом данные на рис. 7 и 8 типичны для материала, состоящего из двух компонентов, характеризующихся высокой и низкой электропроводностью. В нашем композите имеется целый набор элементов, у которых электропроводность существенно разная. Наиболее проводящая фаза - это, вероятно, сеть, образованная компактированными и соединенными между собой частицами ТРГ, т.е. среда типа ТРГ + ТРГ, а наиболее высокоомную (диэлектрическую) фазу образуют, скорее всего, молекулы фуллеренов, связанные между собой ван-дер-ваальсовыми силами, т.е. среда типа $\mathrm{C}_{60}-\mathrm{C}_{60}$. Поскольку между молекулами $\mathrm{C}_{60}$ и окружением однозначно имеется ковалентная связь, в материале присутствуют заметные количества проводящих фаз типа $\mathrm{C}_{60}+\mathrm{C}_{60}$ (фуллереновые полимеры) и $\mathrm{C}_{60}+$ ТРГ (молекулы $\mathrm{C}_{60}$ или их блоки, соединенные с углеродной матрицей с образованием проводящих цепей типа $\mathrm{C}_{60}+\mathrm{TP} \Gamma+\mathrm{C}_{60}+$ ТРГ). Но в любом случае наиболее проводящая фаза, присутствующая в материале в достаточном количестве, будет шунтировать все остальные. Поскольку материал в целом довольно низкоомный, кривые на рис. 7 и 8 отражают характер проводящего компонента. Снижение его концентрации приводит к возрастанию сопротивления всего композита (рис. 8).

3.4. Влияние отжига. Наши образцы типа $\mathrm{C}_{60}+$ ТРГ при всех соотношениях компонентов оказались достаточно прочными. Они легко выдерживали отжиги при температурах до $650^{\circ} \mathrm{C}$ в течение нескольких часов, не теряя прочности и совершенно не изменяя формы, массы и объема, сохраняя также изначальный матовый блеск своей поверхности (при этом даже точечные повреждения поверхности не зафиксированы). Можно предположить, что при отжигах пористость практически не изменяется. Вместе с этим во всех отожженных образцах наблюдается увеличение удельного сопротивления примерно на 30-60\% (в зависимости от температуры измерения), что иллюстрируется на рис. 9, где с учетом пористости, рассчитанной по формуле (5), показаны типичные зависимости $\rho(T)$. Коэффициент Холла при $T=77 \mathrm{~K}$ в синтезированных образцах положителен и зависит от величины $H$ (хотя и довольно слабо), что свидетельствует о присутствии двух подсистем носителей заряда, при этом основными являются дырки. Оценка их концентрации $n_{h}$ по формуле

$$
R_{H}=1 / e n_{h}
$$

(где $e-$ заряд электрона) дает в точке $H=0$, например, для состава $\mathrm{C}_{60}: \mathrm{TP}=1: 1$ (рис. 10) значения $n_{h}=6.3 \cdot 10^{19} \mathrm{~cm}^{-3}$ в неотожженном образце и $n_{h}=4.2 \cdot 10^{19} \mathrm{~cm}^{-3}$ в отожженном. Используя выражение для проводимости

$$
\sigma=1 / \rho=e n_{h} \mu_{h},
$$

получаем соответствующие оценки подвижности: $\mu_{h}=14$ и $15 \mathrm{~cm}^{2} \cdot(\mathrm{V} \cdot \mathrm{s})^{-1}$. Иными словами, рост электросопротивления при отжиге образцов происходит главным образом за счет снижения концентрации по-

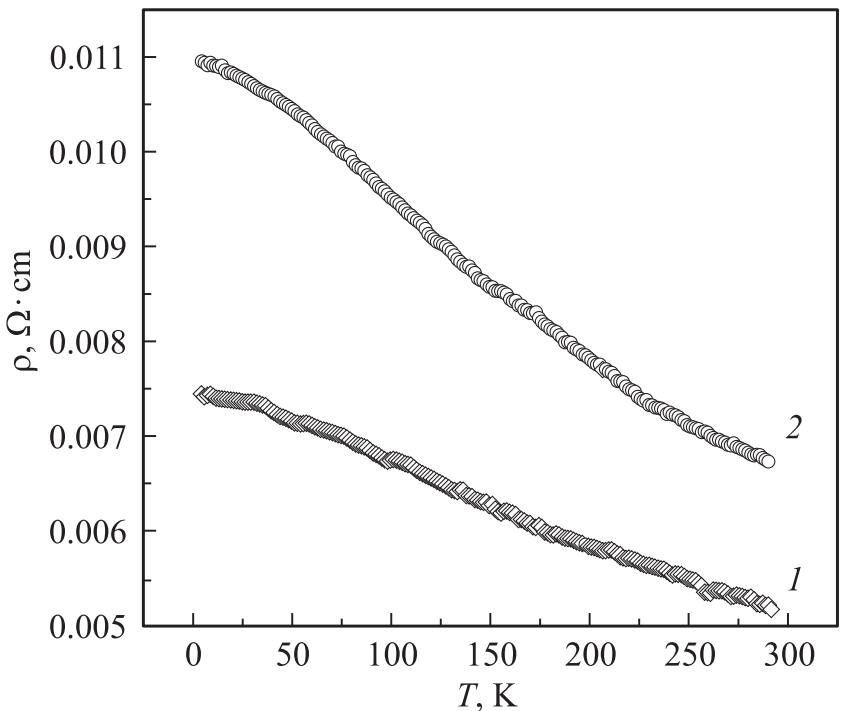

Рис. 9. Зависимости $\rho(T)$ для двух одинаковых по составу образцов $\mathrm{C}_{60}:$ ТРГ $=1: 1.1-$ неотожженный образец, 2 - отожженный образец.

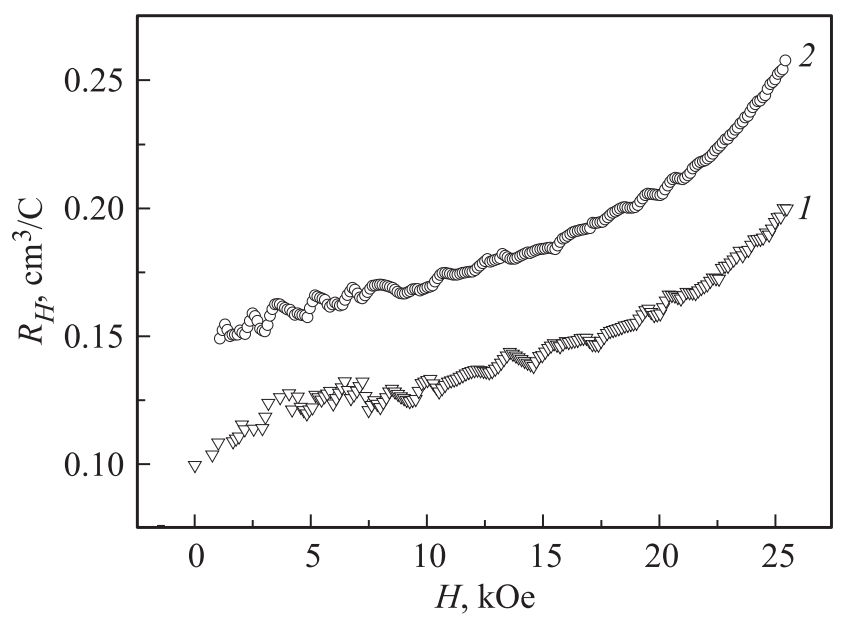

Рис. 10. Зависимости постоянной Холла от напряженности магнитного поля для тех же образцов, что на рис. 9. $T=77 \mathrm{~K}$.

движных носителей заряда. Причиной этого может быть разрыв некоторого количества имеющихся в структуре химических связей из числа наиболее напряженных, что может приводить к появлению дополнительных ловушек носителей заряда.

Отметим также, что, согласно данным рис. 7 и 9, температурный коэффициент сопротивления материала отрицателен, т. е. величина $\rho$ с понижением температуры образцов монотонно увеличивается, причем довольно слабо (в среднем примерно в 1.5 раза во всем диапазоне температур). Такое поведение наряду с дырочной проводимостью при довольно большой концентрации носителей заряда и невысокой их подвижности характерно для разупорядоченных графитовых систем, например нанопористых [23] и биоморфных [24] модификаций углерода. 


\section{4. Заключение}

Получен и исследован углеродный композиционный материал, в котором фуллерены впервые размещены в матрице из терморасширенного графита. Образцы получены путем термообработки при $550-650^{\circ} \mathrm{C}$ исходных механических смесей поликристаллических порошков при разных соотношениях $\mathrm{C}_{60}$ и ТРГ, их прессования при давлении $0.7 \mathrm{GPa}$ и отжига сформованных монолитных образцов при тех же температурах.

Оценена пористость образцов, измерены и проанализированы температурные зависимости удельного электросопротивления, полевые зависимости постоянной Холла, спектры оптического пропускания в области частот колебательных мод молекулы $\mathrm{C}_{60}$, оценено влияние отжигов.

Показано, что ИК-спектры значительно отличаются от исходных спектров свободных молекул $\mathrm{C}_{60}$, удельное электросопротивление при снижении температуры слабо растет и при этом существенно зависит от соотношения компонентов. Величина $\rho$ находится в пределах от единиц $\mathrm{m} \Omega \cdot \mathrm{cm}$ до десятых долей $\Omega \mathrm{cm}$. Концентрация носителей заряда (преимущественно дырок) $\sim 10^{19}-10^{20} \mathrm{~cm}^{-3}$.

На основании полученных результатов сделан вывод, что в синтезированном материале между фуллеренами и окружением устанавливаются ковалентные связи, материал при использованных соотношениях компонентов можно отнести к металлическим системам со структурным беспорядком.

\section{Список литературы}

[1] В.И. Березкин. Углерод: замкнутые наночастицы, макроструктуры, материалы. АРТЭГО, СПб. (2013). 450 с.

[2] Q.Z. Xue, X. Zhang. Carbon 43, 760 (2005).

[3] I. Lazar, G. Lazar. J. Non-Cryst. Solids 352, 2096 (2006).

[4] O. Gunnarson. Rev. Mod. Phys. 69, 575 (1997).

[5] V. Buntar, H.W. Weber. Supercond. Sci. Technol. 9, 599 (1996).

[6] В.И. Березкин. Письма в ЖЭТФ 83, 455 (2006).

[7] В.И. Березкин, В.В. Попов. ФТТ 49, 1719 (2007).

[8] А.С. Фиалков. Углерод, межслоевые соединения и композиты на его основе. Аспект Пресс, М. (1997). 718 с.

[9] Справочник химика / Под ред. Б.П. Никольского. Гос. науч.-техн. изд-во хим. лит., Л.-М. (1962). Т. 1. 1071 с.

[10] B. Sundqvist. Adv. Phys. 48, 1 (1999).

[11] Quasicrystals, networks and molecules of fivefold symmetry / Ed. I. Hargittai. VCH Publ, N.Y. (1990). XIII, 314 p.

[12] D.D. Klug, J.A. Howard, D.A. Wilkinson. Chem. Phys. Lett. 188, 168 (1992).

[13] M. Matus, H. Kuzmany. Appl. Phys. A 56, 241 (1993).

[14] M.C. Martin, X. Du, J. Kwon, L. Mihaly. Phys. Rev. B 50, 173 (1994)

[15] M.S. Dresselhaus, G. Dresselhaus, P.C. Eklund. Science of fullerenes and carbon nanotubes. Academic Press, San Diego, etc. (1996). XV, $965 \mathrm{p}$.

[16] M.E. Kozlov, K. Yakushi. J. Phys.: Condens. Matter 7, L209 (1995).
[17] V.A. Davydov, L.S. Kashevarova, A.V. Rakhmanina, V.M. Senyavin, R. Ceolin, H. Szwarc, H. Allouchi, V. Agafonov. Phys. Rev. B 61, 11936 (2000).

[18] А.В. Елецкий, Б.М. Смирнов. УФН 165, 977 (1995).

[19] М.П. Шаскольская. Кристаллография. Высш. шк., М. (1984). 375 c.

[20] C.A. Klein. Rev. Mod. Phys. 34, 56 (1962).

[21] Т.Л. Макарова. ФТП 35, 257 (2001).

[22] Y. Saito, H. Shinohara, M. Kato, H. Nagashima, M. Ohkohchi, Y. Ando. Chem. Phys. Lett. 189, 236 (1992).

[23] В.В. Попов, С.К. Гордеев, А.В. Гречинская, А.М. Данишевский. ФТТ 44, 758 (2002).

[24] В.В. Попов, Т.С. Орлова, J. Ramirez-Rico. ФТT 51, 2118 (2009). 